www4.fsanet.com.br/revista

Rev. FSA, Teresina, v. 18, n. 01, art. 15, p. 327-353, jan. 2021

ISSN Impresso: 1806-6356 ISSN Eletrônico: 2317-2983 http://dx.doi.org/10.12819/2020.18.01.15

\title{
O Cenário de (Des)Institucionalização em Saúde Mental do Piauí a Partir das EAPS
}

The Piauí Mental Health (De) Institutionalization Scenario From EAPS

Lucia Cristina dos Santos Rosa

Pós-doutorado em Saúde Coletiva pela Universidade Estadual de Campinas Doutora em Serviço Social pela Universidade Federal do Rio de Janeiro Professora da Universidade Federal do Piauí E-mail: luciacsrosa@gmail.com

Sâmia Luiza Coêlho da Silva

Doutorado em Políticas Públicas pela Universidade Federal do Piauí Mestra em Políticas Públicas pela Universidade Federal do Piauí Professora da Faculdade Maranhense São José dos Cocais E-mail: samialuiza@hotmail.com

Endereço: Lucia Cristina dos Santos Rosa

Universidade Federal do Piauí - Av. Universitária, S/N, Bairro: Ininga, CEP: 64.049-550, Teresina/PI, Brasil.

Endereço: Sâmia Luiza Coêlho da Silva

Rua Aquiles Lisbôa, 399, Bairro: Centro, CEP: 65.630300, Timon/MA, Brasil.
Editor-Chefe: Dr. Tonny Kerley de Alencar Rodrigues

Artigo recebido em $05 / 10 / 2020$. Última versão recebida em 22/10/2020. Aprovado em 23/10/2020.

Avaliado pelo sistema Triple Review: a) Desk Review pelo Editor-Chefe; e b) Double Blind Review (avaliação cega por dois avaliadores da área).

Revisão: Gramatical, Normativa e de Formatação 


\title{
RESUMO
}

Este estudo objetiva explorar o cenário de (des)institucionalização piauiense, como fruto da Reforma Psiquiátrica, a partir das Equipes de Avaliação e Acompanhamento de Medidas Terapêuticas Aplicáveis à Pessoa com Transtorno Mental em Conflito com a Lei (EAPs). Para tal o debate se centraliza em explicitar as EAPs como configuração peculiar estabelecida pelas necessidades do Estado do Piauí em torno do segmento de pessoas com transtornos mentais em conflito com a lei. A pesquisa caracterizou-se por ser de natureza qualitativa, com emprego da observação simples, de entrevista semiestruturada e pesquisa documental. Os achados sinalizam que o processo de desinstitucionalização consolidado no Piauí, revela, além das demais estratégias de desinstitucionalização como estabelecido em legislação, uma realidade singular manifestada pela formação das EAPs que tem executado um processo de trabalho circundado de desafios, porém com produtos que apontaram para a construção da vertente desinstitucionalizante como (des)construção.

Palavras-Chave: Reforma Psiquiátrica. Desinstitucionalização. EAPs.

\begin{abstract}
This study aims to explore the scenario of Piaui's (de) institutionalization, as a result of Psychiatric Reform, from the Teams of Evaluation and Monitoring of Therapeutic Measures Applicable to the Person with Mental Disorder in Conflict with the Law (WBS). To this end, the debate focuses on making EAPs explicit as a peculiar configuration established by the needs of the State of Piauí around the segment of people with mental disorders in conflict with the law. The research was characterized by being of a qualitative nature, using simple observation, semi-structured interviews and documentary research. The findings indicate that the consolidated deinstitutionalization process in Piauí reveals, in addition to the other deinstitutionalization strategies as established in legislation, a unique reality manifested by the formation of the WBSs that has been carrying out a work process surrounded by challenges, but with products that the construction of the deinstitutionalizing aspect as (de) construction.
\end{abstract}

Keywords: Psychiatric Reform. Deinstitutionalization. EAPs. 


\section{INTRODUÇÃO}

As alterações na política de saúde mental brasileira, em curso desde a década de 1990, englobam a reestruturação da assistência em saúde mental e são circunscritas ao movimento da Reforma Psiquiátrica no Brasil, concebido pelo Ministério da Saúde como o “[...] conjunto de transformações de práticas, saberes, valores culturais e sociais em torno do 'louco' e da 'loucura', mas especialmente em torno das políticas públicas para lidar com a questão" (BRASIL, 2007, p. 58). Esse conjunto de alterações resultou em processos de desinstitucionalização, que se dão pela desconstrução de aparatos legislativos, ideológicos, técnico-assistenciais e políticos (AMARANTE, 1996), que segregavam a pessoa com transtorno mental (PcTM) do convívio social e do direito de viver na cidade.

Amarante (1997) aponta que a desinstitucionalização consiste em um processo contínuo, observada como estratégia permanente que diz respeito aos entendimentos culturais, sociais e técnicos no lidar com o sofrimento, com as situações de diferenças e diversidades. Dessa forma, tomada como paradigma na Reforma Psiquiátrica, a desinstitucionalização tem uma concepção muito mais ampla, ao permear todos os componentes oferecidos pela política de saúde mental sob a égide antimanicomial indo além, pois demanda uma mudança sociocultural.

No Piauí, o processo de desinstitucionalização em saúde mental, ainda se encontra em construção, e foi figurado de forma tardia, tendo seu início em meados de 2004, quando surgiu o primeiro Centro de Atenção Psicossocial (CAPS) no Estado, como um dos primeiros serviços de natureza substitutiva (um atraso de cerca de 17 anos em relação à criação do primeiro serviço no Brasil).

Dentre os prospectos que marcam o cenário desinstitucionalizante do Estado encontram-se os SRTs e o Programa de Volta para Casa, ambos previstos na portaria $\mathrm{n}^{\circ}$ 3.088/2011 que lança a Rede de Atenção Psicossocial (RAPS). Todavia, para além dessas estratégias, observadas como eixo de atenção da RAPS, o Piauí foi marcado por um panorama diferenciado que se revelou por meio do trabalho das EAPs, que na pesquisa realizada foi observado, por sua peculiaridade, como mecanismo desinstitucionalizante para as PcTMs em conflito com a lei.

As EAPs foram estabelecidas pela portaria $\mathrm{n}^{\circ} .94$ de 14/01/14 e se caracterizam como um dispositivo de mediação entre a esfera da justiça e os órgãos responsáveis pela atenção psicossocial, no âmbito do Sistema Único de Saúde, tendo como objetivo subsidiar a 
aplicação da medida terapêutica aos "pacientes" judiciários e garantir o acompanhamento integral e contínuo no contexto familiar e social, por meio das RAPS (BRASIL, 2014).

No Piauí, as EAPs foram cadastradas, no Ministério da Saúde, em duas equipes no final de 2014, buscando redirecionar as ações e o tratamento destinado às PcTMs em conflito com a lei que foram transinstitucionalizadas para o Hospital Areolino de Abreu (HAA), após interdição do Hospital Valter Alencar (HPVA) que até meados de 2012 funcionava como "referência" enquanto Hospital de Custódia e Tratamento Psiquiátrico (HCTP) para esse segmento.

Desta feita, o artigo em tela buscará apresentar o cenário de desinstitucionalização piauiense focando nas estratégias estabelecidas, em especial nas EAPs, que, apesar de não necessariamente serem observadas, inclusive legalmente, como mecanismo desinstitucionalizante, têm se conjecturado com uma missão singular que se voltou a garantia da individualização das medidas terapêuticas aplicáveis à PcTM em conflito com a lei para viabilizar o acesso e a qualidade do tratamento e acompanhar a execução das medidas terapêuticas em todas as fases do processo criminal.

Originalmente, este estudo é fruto e se consolida como recorte da tese de doutorado construída junto ao Programa de Pós-Graduação em Políticas Públicas da Universidade Federal do Piauí, tendo por campo empírico as duas EAPs do Estado do Piauí. Adotou-se a pesquisa qualitativa, tendo por principais técnicas a observação, entrevistas semiestruturadas e a pesquisa documental. A investigação foi aprovada pelo Comitê de Ética da Universidade Federal do Piauí, sob a aprovação CAEE 15688619.0.0000.5214, e parecer consubstanciado $\mathrm{n}^{\mathrm{o}} 3.429 .155$, datado de 01 de julho de 2019 .

\section{REFERENCIAL TEÓRICO}

\subsection{A desinstitucionalização como produto do Movimento de Reforma Psiquiátrica: Caminhos e configuração no Brasil}

A desinstitucionalização, enquanto um dos produtos do processo de reorientação do modelo assistencial em saúde mental, é apontada como um dos pressupostos elementares do Movimento de Reforma Psiquiátrica, consolidado como fundamental para a política de saúde mental.

No Brasil, o Movimento de Reforma Psiquiátrica ocorreu fundamentado no contexto da Psiquiatria Democrática Italiana, que apregoava que os hospitais psiquiátricos eram 
espaços de violência e deveriam ser fechados e automaticamente substituídos por serviços territoriais de atenção diária (AMARANTE, 1995). Embora baseado marcadamente nesse modelo, o processo brasileiro de Reforma Psiquiátrica possui uma trajetória própria, marcada por forte movimentação política e pelos desafios de um país constitucionalmente desigual, da periferia, do capitalismo em desenvolvimento (DELGADO et al., 2007).

Desta feita, o Movimento da Reforma Psiquiátrica brasileira, conceituada como “[...] conjunto de transformações de práticas, saberes, valores culturais e sociais em torno do 'louco' e da 'loucura', mas especialmente em torno das políticas públicas para lidar com a questão" (BRASIL, 2007, p. 58), inicialmente persistiu subsumido ao Movimento Sanitário, mas ganhou uma identidade própria, haja vista que as primeiras tiveram como bandeira de luta a universalidade do direito à saúde, tendo por foco os direitos sociais (ROSA, 2013). Destarte, o movimento se consolidou ainda na busca de politizar a questão da saúde mental, especialmente na luta contra as instituições psiquiátricas, produzindo reflexões críticas que provocaram uma ruptura epistemológica. Além disso, criou experiências e estratégias de cuidado contra hegemônicas, conquistou mudanças em normas legais e buscou produzir efeitos no campo sociocultural (YASUI, 2006).

De acordo com Amarante (2012), historicamente, o processo de Reforma Psiquiátrica no Brasil teve sua origem no final da década de 1970, no contexto da redemocratização nacional, ou seja, na luta contra a ditadura militar. Rosa (2013) expõe que o movimento reformista orientou-se prioritariamente em torno da luta pelos direitos civis das pessoas com transtornos mentais, isto é, inseriu-se na luta das minorias sociais pelo reconhecimento social e pelas liberdades básicas, tais como vocalizar suas próprias necessidades, circular pela cidade, tendo garantido o convívio social/ comunitário por meio da inserção de serviços substitutivos, mas não abdicando dos direitos sociais. Ao contrário, exigindo-os de maneira conjugada. Ademais, tal movimento contribuiu significativamente para mudança na hegemonia do modelo hospitalocêntrico, levando a um repensar nas formas de cuidado e relações sociais das pessoas com transtornos mentais (PcTMs).

Mas o caminho da Reforma Psiquiátrica não avançou sem percalços. Ao longo de toda a década de 1980 e 1990, os gestores da psiquiatria privada pressionaram politicamente pela manutenção do convênio com o Governo e o não fechamento dos manicômios (SOARES, 1997). Todavia, apesar dessa pressão, a implantação dos serviços substitutivos intensificou-se e imperou a partir de 1992 (VIDAL et al., 2008), ano em que foi realizada a II Conferência Nacional de Saúde Mental (CNSM) com o tema "A reestruturação da atenção em saúde 
mental no Brasil: modelo assistencial o direito à cidadania", determinando uma rede de atenção integral à saúde mental, respeitando a PcTM em sua individualidade e direito.

Ressalta-se que nessa Conferência, foram aprovados os princípios e diretrizes da Reforma Psiquiátrica na linha da desinstitucionalização ${ }^{1}$ e de luta antimanicomial (AMARANTE, 1995), destacando-se entre 1991 e 1992, a aprovação das portarias 189/91 e 224/92 do Ministério da Saúde, que criaram uma possibilidade até então inexistente para o Sistema Único de Saúde: a de financiar programas de assistência extramuros para as PcTMs e seus familiares, tais como programas de orientação, lares abrigados, Núcleos de Atenção Psicossociais (NAPS), entre outros (WAIDMAN, 2004; AMARANTE, 1995). A portaria 224/92 oficializou, ainda, as normas de funcionamento dos CAPS, especificando suas atribuições e diferenciando os tipos de CAPS por ordem crescente de porte, complexidade e abrangência populacional (BRASIL, 1992).

Amarante (2012) também aponta que, nesse mesmo período (em meados da década de 1990), teve início, na cidade de Santos $^{2}$ em São Paulo, a primeira experiência de uma cidade brasileira a adotar uma política municipal orientada pelos princípios da Reforma Psiquiátrica, com a construção de uma rede de serviços, estratégias e dispositivos que passaram a ser denominados serviços substitutivos. Criaram-se serviços de emergência psiquiátrica no hospital geral; um vigoroso e criativo projeto cultural, o Projeto TAM TAM, com rádio e TV comunitária; uma residência para ex-internos do hospital que, por alguma razão, não tivessem condições próprias de moradia; e uma cooperativa de trabalho, para geração de renda para os usuários.

Para Amarante (2012, p. 643)

O forte impacto e a repercussão da experiência santista estão na base das condições de possibilidade do aparecimento, em outubro de 1989, do projeto de lei (PL n.

\footnotetext{
${ }^{1}$ Amarante (1996) distingue 3 vertentes de desinstitucionalização: como desospitalização, tal como ocorreu nos Estados Unidos, implementada como medida administrativa, de contenção de gastos; como desassistência, decorrente da ausência de suporte estatal para a continuidade de cuidados e desconstrução, na visão basagliana, que produziu alterações paradigmáticas, assistenciais e legais, produzindo uma outra relação entre a sociedade e a loucura.

${ }^{2}$ A cidade de Santos vivenciou um acontecimento importante do processo de reforma psiquiátrica no Brasil: a intervenção realizada pela prefeitura em um hospital psiquiátrico privado conveniado ao SUS, a Clínica Anchieta, onde ocorriam violências contra pacientes internados, assim como vários óbitos. A partir dessa intervenção, duas opções do poder público municipal de Santos deram início a uma verdadeira revolução na questão do tratamento da loucura no país. A primeira opção foi à decisão de não reformar o hospital. Ao contrário, partiu-se do princípio de que o hospital psiquiátrico, por sua natureza e função social, era uma instituição de violência e segregação. Em segundo lugar, tendo como base a experiência iniciada por Basaglia e continuada por Rotelli, decidiu-se por atuar no sentido da desconstrução do ideário manicomial, entendido não apenas como o hospital psiquiátrico em si, mas como todas as referências conceituais e ideológicas produzidas no âmbito do saber psiquiátrico em torno do conceito da doença mental (AMARANTE, 2012) e, nesse sentido, foi que se iniciou a construção de serviços de base comunitária destinados as PcTMs.
}

Rev. FSA, Teresina, v. 18, n. 01, art. 15, p. 327-353, jan. 2021

www4.fsanet.com.br/revista 
3.657/89), de autoria do deputado Paulo Delgado, que propunha a extinção progressiva dos manicômios e sua substituição por outros serviços de saúde mental. Apesar da rápida aprovação na Câmara dos Deputados, um ano depois, o projeto ficou em tramitação por quase 12 anos e acabou sendo rejeitado no Senado. Contudo, deu origem ao surgimento de um substitutivo, aprovado com a lei n. $10.216 / 01$, que, apesar de abandonar algumas das propostas mais importantes do projeto - tais como extinção progressiva dos manicômios -, possibilitou muitas inovações no campo do modelo assistencial e dos direitos humanos e da cidadania das pessoas em sofrimento mental.

A lei n. 10.216, de 06 de abril de 2001, trata fundamentalmente dos direitos e da proteção das PcTMs, além de estimular o tratamento em regime comunitário e não hospitalar. Como aborda Amarante (2007), a lei instituiu a reforma no modelo assistencial em saúde mental. Se antes havia um modelo denominado hospitalocêntrico, centrado na internação das PcTMs em hospitais psiquiátricos, a partir de então institui-se um modelo de atenção psicossocial (também conhecido como modelo comunitário) que privilegia o cuidar em liberdade e objetiva oferecer atendimento multiprofissional na comunidade e reinserir as PcTMs na sociedade.

Pinto e Ferreira (2010) destacam que, após a promulgação da Lei 10.216, outras oito leis estaduais e diversas portarias e programas foram criados para regulamentação do atendimento psiquiátrico comunitário. Merece destaque o Programa De Volta Para Casa, criado pela Lei Federal 10.708/2003 (BRASIL, 2003), os Serviços Residenciais Terapêuticos ${ }^{3}$ oficializados a partir da portaria $\mathrm{n}^{\mathrm{o}} 106$, de fevereiro de 2000 e a portaria $336 / \mathrm{GM}$, que atribui aos CAPS o papel central na psiquiatria comunitária brasileira (DELGADO et al., 2007).

Ademais, a Lei da Reforma Psiquiátrica brasileira tem como eixos: 1) a descentralização da atenção na internação hospitalar em manicômios para o cuidado comunitário, preservando o cuidar em liberdade, ou seja, os direitos civis, anteriormente suprimidos; 2) a diversificação da rede de Atenção à Saúde Mental, implicando a reconstituição da complexidade das necessidades sociais subjacentes à experiência e vida com a enfermidade, ativando a intersetorialidade e 3) o processo de desinstitucionalização como desconstrução dos aparatos manicomiais, legislativos e culturais.

Destarte, acerca da desinstitucionalização como eixo da Reforma Psiquiátrica destacase a abordagem de Rotelli (1990, p. 33) que considera a desinstitucionalização

[...] sobretudo um trabalho terapêutico, voltado para a reconstituição das pessoas, enquanto pessoas que sofrem, como sujeitos. [...] Depois de ter descartado a 'solução-cura' se descobriu que cuidar significa ocupar-se, aqui e agora, de fazer

\footnotetext{
${ }^{3}$ Ressalta-se que o Programa de Volta para Casa e os Serviços Residenciais Terapêuticos serão abordados mais adiante como Estratégias de Desinstitucionalização.
}

Rev. FSA, Teresina PI, v. 18, n. 01, art. 15, p. 327-353, jan. 2021

www4.fsanet.com.br/revista 
com que se transformem os modos de viver e sentir o sofrimento do 'paciente' e que, ao mesmo tempo, se transforme sua vida concreta e cotidiana, que alimenta este sofrimento (ROTELLI, 1990, p.33).

Em sua origem, os pressupostos da desinstitucionalização encaminham-se no sentido da restituição da subjetividade do indivíduo, possibilitando-lhe a recuperação de sua contratualidade, isto é, da posse de recursos para trocas sociais e, por conseguinte, para a cidadania social. Contudo, alguns estudos sobre as mudanças operadas na assistência no âmbito da Reforma Psiquiátrica brasileira apontam para a compreensão da desinstitucionalização como desospitalização, ou seja, apenas retirar o sujeito do complexo hospitalar e enviá-lo para casa.

Segundo Spricigo (2002), a desinstitucionalização, não correlata da desospitalização, torna-se a um só tempo, processo de desconstrução que traz consigo uma nova forma de se relacionar e de lidar com a PcTM, fundada na possibilidade de estabelecer uma relação em que exista reciprocidade entre a PcTM e a sociedade. Isso gera a necessidade de invenção de novas modalidades de mediação, não somente médicas, mas principalmente políticas, sociais e culturais.

Sobre esta questão, Amarante (1995) enfatiza que a mudança desejada na assistência em saúde mental não corresponde simplesmente ao fechamento de hospitais psiquiátricos e o consequente abandono das pessoas em suas famílias ou nas ruas, nem no fechamento de leitos para reduzir custos, no sentido do neoliberalismo ou no sentido do enxugamento do Estado. Segundo o autor,

[...] desinstitucionalização não significa apenas desospitalização, mas desconstrução. Isto é, superação de um modelo arcaico centrado no conceito de doença como falta e erro, centrado no tratamento da doença como entidade abstrata. Desinstitucionalização significa tratar o sujeito em sua existência e em relação com suas condições concretas de vida. Isto significa não administrar-lhe apenas fármacos ou psicoterapias, mas construir possibilidades. O tratamento deixa de ser a exclusão em espaços de violência e mortificação para tornar-se criação de possibilidades concretas de sociabilidade a subjetividade. O doente, antes excluído do mundo dos direitos e da cidadania, deve tornar-se um sujeito, e não um objeto do saber psiquiátrico. A desinstitucionalização é este processo, não apenas técnico, administrativo, jurídico, legislativo ou político; é, acima de tudo, um processo ético, de reconhecimento de uma prática que introduz novos sujeitos de direito e novos direitos para os sujeitos. De uma prática que reconhece, inclusive, o direito das pessoas mentalmente enfermas em terem um tratamento efetivo, em receberem um cuidado verdadeiro, uma terapêutica cidadã, não um cativeiro. Sendo uma questão de base ética, o futuro da reforma psiquiátrica não está apenas no sucesso terapêutico-assistencial das novas tecnologias de cuidado ou dos novos serviços, mas na escolha da sociedade brasileira, da forma como vai lidar com os seus diferentes, com suas minorias, com os sujeitos em desvantagem social (AMARANTE, 1995, p. 491-494). 
Neste sentido, a proposta da desinstitucionalização está centrada em uma mudança completa do paradigma de saber em saúde mental e, do ponto de vista assistencial, na constatação de que o hospital psiquiátrico tradicional é antiterapêutico. Assim, a estratégia de conversão do sistema de cuidado deve partir da substituição do hospital psiquiátrico por um amplo rol de serviços abertos e comunitários, capazes de assistir o usuário desde a crise aguda até as necessidades mais amplas de caráter social, de forma a garantir cidadania (SCALZAVARA, 2006).

Nesse sentido, destacam-se algumas ações que foram desenvolvidas para colocar em prática a política de saúde mental, tendo por base o prospecto da desinstitucionalização, segundo Brasil (2002): Redução progressiva dos leitos psiquiátricos de hospitais em hospital psiquiátrico; Qualificação, expansão e fortalecimento da rede extra-hospitalar; Programa permanente de formação de recursos humanos para a Reforma Psiquiátrica; Implantação do Programa de Volta para Casa; Implementação da Política de Atenção Integral a usuários de álcool e outras drogas; Inclusão das ações de saúde mental na Atenção Básica.

Com base na necessidade de se colocar em prática as ações previstas na política de saúde mental foram criados serviços de saúde e programas enquanto estratégias de desinstitucionalização voltados para a qualificação, expansão e fortalecimento da rede extrahospitalar, com o objetivo de inserir a PcTM em atividades diárias, no convívio familiar e na sociedade. Como exemplo se pontua serviços capazes de ser uma referência institucional permanente de cuidados (os CAPS), serviços residenciais terapêuticos (SRTs) e outros serviços ambulatoriais de referência. Igualmente foram incorporados ao campo da saúde cuidados e procedimentos tais como renda (Programa de volta para Casa), trabalho protegido (Programa geração de renda e trabalho), lazer assistido (Centros de Convivência e Cultura) e outras formas de intervenção intersetorial ampliada.

Dessa forma, é composta uma Rede de Atenção Psicossocial (RAPS) embasada na desinstitucionalização. A RAPS é lançada pela portaria de nº 3.088 do Ministério da Saúde em 2011, conformando uma rede de serviços no âmbito do SUS para além do CAPS e sendo vista enquanto fundamental para a consolidação da Reforma Psiquiátrica, pois "a articulação em rede dos variados serviços substitutivos ao hospital psiquiátrico é crucial para a constituição de um conjunto vivo e concreto de referências capazes de acolher a pessoa em sofrimento mental" (BRASIL, 2005, p.35). 
Ressalta-se que a RAPS possui como um dos seus componentes ${ }^{4}$ as "Estratégias de Desinstitucionalização" que estão voltadas à garantia do cuidado integral, da promoção de autonomia, do exercício da cidadania e da progressiva inclusão social às pessoas com transtorno mental e com necessidades decorrentes do uso de crack, álcool e outras drogas, em situação de internação de longa permanência. No Estado do Piauí, tais estratégias têm se caracterizado principalmente pela adoção dos SRTs que emergem ainda no ano de 2006, do Programa de Volta pra Casa ${ }^{5}$ e das Equipes de Avaliação e Acompanhamento de Medidas Terapêuticas Aplicáveis à Pessoa com Transtorno Mental em Conflito com a Lei (EAP), esta última observada como uma particularidade do cenário piauiense, haja vista ser um serviço recente (consolidado no ano de 2015) e pioneiro a nível nacional, como veremos no item de discussão e análise desse trabalho, onde serão debatidos o panorama e as particularidades locais no tocante à desinstitucionalização.

\section{METODOLOGIA}

A metodologia do trabalho foi tomada como uma etapa dinâmica que pressupôs a contínua problematização e atualização do referencial teórico adotado, compreendendo-se que esta ocupa lugar central no interior do conhecimento, uma vez que ela faz parte intrínseca da visão social de mundo, veiculada na teoria, constituindo-se o "caminho do pensamento", segundo Habermas (1987), citado por Minayo (2008).

Nesse contexto, a pesquisa caracterizou-se por ser de cunho qualitativo, pois se preocupou em analisar e interpretar aspectos mais densos, descrevendo a complexidade dos processos sociais (MINAYO, 2008) que, no caso, se condensaram pela realidade desinstitucionalizante do cenário piauiense.

Ademais, quanto aos objetivos a pesquisa enquadrou-se numa pesquisa exploratória, visto que buscou constatar algo em um determinado local, objetivando proporcionar maior familiaridade com o assunto abordado, e materializou-se por se constituir como descritiva e analítica, pois se tratou de um estudo que abrangeu a caracterização de um grupo, no caso representado pelos atores envolvidos no processo de desinstitucionalização, tendo o intuito de

\footnotetext{
${ }^{4}$ De acordo com Brasil (2011) a Rede de Atenção Psicossocial é constituída pelos seguintes componentes: IAtenção Básica em Saúde; II- Atenção Psicossocial Especializada; III- Atenção de Urgência e Emergência; IVAtenção Residencial de Caráter Transitório; V- Atenção Hospitalar; VI- Estratégias de Desinstitucionalização; VII- Reabilitação Psicossocial.

${ }^{5}$ Instituído pela Lei Federal n ${ }^{\circ}$ 10.708, de 31 de julho de 2003, integra a Rede de Atenção Psicossocial no componente Estratégias de Desinstitucionalização por meio do pagamento de um benefício $\mathrm{R} \$ 412,00$ reais mensais por pessoa para pessoas egressas de hospitais psiquiátrico e/ou custódia. O Estado possui 23 beneficiários.
} 
identificar e analisar suas opiniões, atitudes e crenças (GIL, 2008) buscando interpretá-las de forma a aprofundar o conhecimento acerca dos fenômenos que as cercam, além de buscar responder ao problema da pesquisa.

A pesquisa tratou-se também de um estudo de caso por referir-se a um estudo limitado a um grupo particular que foram os profissionais, os familiares e as pessoas com transtornos mentais partícipes do processo de desinstitucionalização, envolvendo um grupo intensamente estigmatizado socialmente, com vários anos de institucionalização e alguns denominados "louco infrator", aquele que no geral, tendo um transtorno mental diagnosticado cometeu um homicídio, no geral, vitimizando alguém do próprio contexto familiar ou comunitário. O cenário configurou-se num panorama peculiar que foi o contexto piauiense a partir de serviços específicos, dentre eles como as EAPs.

Levando em consideração os procedimentos que foram empregados, a pesquisa foi considerada do tipo bibliográfica e documental. A pesquisa bibliográfica foi contínua, e teve por foco a revisão da literatura pertinente ao tema, com a construção do "estado da arte" recorrendo-se a livros disponíveis, assim como bases digitais e virtuais de informação, como a Biblioteca Digital de Dissertações e Teses, Biblioteca Virtual em Saúde, dentre outros. Além da pesquisa literária foi realizado levantamento de dados virtuais em sites oficiais que também foram utilizados como fonte de obtenção de material, principalmente no que se refere a legislações, portarias, decretos, dados ou notícias referentes à política de saúde mental, com enfoque na questão da desinstitucionalização em âmbito nacional e estadual.

E quanto à pesquisa documental esta foi realizada a partir da busca de informações que puderam contribuir para a compreensão do objeto de pesquisa, sendo feita por meio de documentos nos locais onde foi concretizada a investigação empírica, a Gerência Estadual de Saúde Mental, localizada na Secretaria Estadual da Saúde do Piauí, no Centro Administrativo, em Teresina. Contou como principais documentos: planos de ação e relatórios dos serviços e/ou de profissionais; livros de registros e/ou atas de reuniões; fichas de acompanhamento de usuários e/ou prontuários, além de documentos em geral que explicitaram o funcionamento e a dinâmica dos serviços e que puderam contribuir para a percepção dos perfis das PcTMs e suas famílias.

A investigação se valeu ainda, no tocante à coleta de informações, de pesquisa de campo que teve como cenário o Estado do Piauí e como arena de investigação as Equipes de Avaliação e Monitoramento da Medida Terapêutica da Pessoa com Transtorno Mental em Conflito com a Lei (EAP) enquanto serviço gerido pela Secretaria Estadual de Saúde do Piauí - SESAPI, dentre outros serviços como, por exemplo, os SRTs, bem como profissionais, 
familiares das PcTMs na perspectiva do processo de desinstitucionalização e PcTMs desinstitucionalizadas.

Além do mais, acredita-se que os "fenômenos ou processos têm que ser entendidos nas suas determinações e transformações dadas pelos sujeitos" (MINAYO, 2002, p. 25), sendo estes o universo populacional privilegiado pela pesquisadora, ou seja, as pessoas que fazem parte do fenômeno a ser desvelado.

Tomando isso como base para o estudo em pauta, a amostra de participantes da pesquisa se materializou em 14 sujeitos, a saber: familiares (03), pessoas com transtornos mentais (06) e profissionais (05) envolvidos no processo de desinstitucionalização do Estado e que integravam as duas EAPs.

Quanto às técnicas de investigação, destaca-se que essas se caracterizam por englobar instrumentos e procedimentos de uma pesquisa (GIL, 2002). No estudo em pauta, tais técnicas visaram fazer a mediação entre os marcos teórico-metodológicos e a realidade empírica, sendo priorizados os seguintes para a sua realização: entrevistas semiestruturadas, observação simples, diário de campo e análise documental.

No tocante à entrevista, a que foi considerada e utilizada nesse estudo foi a do tipo semiestruturada e foram realizadas considerando as questões éticas de uma pesquisa, e materializadas com os participantes que consentiram em fazer parte do estudo, como voluntários, por meio do "Termo de Consentimento Livre e Esclarecido (TCLE)" como apontado pelo Comitê de Ética em Pesquisa (CEP), respeitando-se o universo cultural e os valores sociais e individuais dos colaboradores. O período de realização da coleta de informações se condensou nos meses de julho de 2019 até março de 2020, após aprovação do projeto de pesquisa pelo CEP.

Para o estudo buscaram-se participantes que puderam trazer informações mais significativas, dando-se preferência a locais e sujeitos estratégicos para desvelar o objeto estudado.

A pesquisa proposta também levou em consideração a observação, sendo utilizada no estudo a observação simples que, segundo Gil (2008), caracteriza-se por ser aquela em que o pesquisador observa, de maneira espontânea, os fatos que ocorrem em determinado grupo ou situação. A observação, em qualquer nível de profundidade em que for realizada ou em que teoria se baseie, tradicionalmente utiliza um instrumento denominado diário de campo, que no caso do estudo, foi empregado como recurso metodológico para exercer a reflexão e a narração dos acontecimentos diários e situações vivenciadas na pesquisa, constituindo-se como elemento primordial para complementar a observação, pois o registro do que foi sendo 
observado constituiu-se como "peça" chave para assegurar a preservação da "memória" dos acontecimentos da pesquisa, amadurecimentos e algumas reflexões da pesquisadora.

$\mathrm{Na}$ pesquisa foi empregada também a triangulação metodológica, objetivando uma combinação de perspectivas e de métodos de pesquisa adequados, que fossem apropriados para levar em conta o máximo possível de aspectos distintos de um mesmo problema.

Além da triangulação, os dados foram ainda organizados e analisados a partir do método da dialética de Marx. As informações coletadas foram analisadas criticamente, buscando ir além da aparência dos fatos, estabelecendo conexões entre eles e a realidade mais geral, levando em consideração os aspectos objetivo/subjetivos e, ainda, os movimentos, processos, dinâmicas, contradições, avanços, recuos, dificuldades, partes da própria configuração do objeto de estudo (ARCOVERDE, 2013). Desta feita, o método foi utilizado buscando compreender a processualidade da desinstitucionalização a partir das estratégias adotadas pelo Estado do Piauí, em especial, pelas EAPs, e como se configurou o jogo de forças e a dialética existente no estabelecimento dessas estratégias e na relação com os partícipes do processo de desinstitucionalização.

Nesse sentido, a pesquisa proposta levou em consideração a análise constituída como meio de conseguir respostas às indagações, procurando estabelecer as relações necessárias entre as informações construídas e os pressupostos teóricos.

\section{RESULTADOS E DISCUSSÃO}

\subsection{A (des)institucionalização do Piauí a partir das EAPs: avanços e desafios de um cenário singular}

O processo de reforma psiquiátrica, apesar de se constituir enquanto política nacional se conformou de forma singular em cada Estado da federação, a partir da história e correlação de forças locais. No Piauí, o processo de (des)institucionalização ainda encontra-se em construção, haja vista o próprio começo ter sido tardio na realidade local, pois se iniciou a partir de meados dos anos 2000 quando se instituiu o estabelecimento dos CAPS. Rosa (2011) relata que o surgimento dos CAPS data de 2004, retratando um atraso de 17 anos em relação à criação do primeiro serviço substitutivo dessa natureza no Brasil.

Vários acontecimentos convergiram, para o alavancamento do processo de desinstitucionalização em saúde mental no cenário piauiense. As políticas indutoras do Ministério da Saúde, para reduzir o número de leitos em hospitais psiquiátricos e os recursos 
migrarem para a criação de serviços substitutivos, com a possibilidade de expansão da rede, com CAPS e SRT. O próprio papel assumido pelo Hospital Areolino de Abreu, que historicamente ocupou o epicentro da assistência e dos embates políticos em saúde mental e também, contraditoriamente, assume a vanguarda do processo de desinstitucionalização do segmento considerado "morador" do manicômio, tendo como acelerador do processo, a crise financeira do Sanatório Meduna, que culmina com seu fechamento, encerrando 200 leitos de saúde mental, o que forçou a construção da rede de atenção psicossocial, sobretudo em Teresina, requerendo do gestor municipal ação conjugada com o gestor estadual, para tanto.

Em Teresina, de acordo com Pereira (2018), a RAPS encontra-se organizada a partir dos seguintes pontos de atenção:

\section{Quadro 1 - Sistematização da RAPS em Teresina.}

\begin{tabular}{|c|c|c|}
\hline Componentes da RAPS (eixos) & $\begin{array}{c}\text { Pontos de atenção (previstos na } \\
\text { Portaria } n^{0} \mathbf{3 0 8 8 / 2 0 1 1 )}\end{array}$ & Serviços existentes em Teresina \\
\hline \multirow[t]{5}{*}{ I - Atenção Básica em Saúde } & Unidades Básicas de Saúde (UBS) & $\begin{array}{c}90 \text { UBS, com } 258 \\
\text { equipes de Saúde da Família }\end{array}$ \\
\hline & Núcleo de Apoio a Saúde da Família & 3 NASFs \\
\hline & Consultório na Rua & 1 equipe de Consultório na Rua \\
\hline & $\begin{array}{c}\text { Apoio aos Serviços do componente } \\
\text { Atenção Residencial de Caráter } \\
\text { Transitório }\end{array}$ & Sem informações \\
\hline & Centros de Convivência e Cultura & Inexistente \\
\hline $\begin{array}{c}\text { II - Atenção } \\
\text { Psicossocial Especializada }\end{array}$ & $\begin{array}{l}\text { Centros de Atenção Psicossocial (nas } \\
\text { diferentes modalidades: I, II, III, ad, } \\
\text { infanto-juvenil, ad III) }\end{array}$ & $\begin{array}{l}1 \text { CAPS AD } \\
2 \text { CAPSi } \\
4 \text { CAPS II } \\
1 \text { CAPS III } \\
\end{array}$ \\
\hline \multirow[t]{4}{*}{$\begin{array}{c}\text { III - Atenção de } \\
\text { Urgência e Emergência }\end{array}$} & $\begin{array}{c}\text { Serviço de Atendimento Móvel de } \\
\text { Urgência (SAMU) }\end{array}$ & SAMU \\
\hline & Sala de Estabilização & \multirow[t]{3}{*}{ Hospital Areolino de Abreu } \\
\hline & $\begin{array}{l}\text { Unidades de Pronto Atendimento } \\
\text { (UPA) } 24 \text { horas }\end{array}$ & \\
\hline & $\begin{array}{l}\text { Portas hospitalares de atenção à } \\
\text { urgência/pronto-socorro }\end{array}$ & \\
\hline $\begin{array}{c}\text { IV - Atenção } \\
\text { Residencial em caráter transitório }\end{array}$ & $\begin{array}{c}\text { Unidades de Acolhimento } \\
\text { Serviços de Atenção em Regime } \\
\text { Residencial }\end{array}$ & Inexistente \\
\hline \multirow[t]{2}{*}{$\begin{array}{l}\text { V - Atenção } \\
\text { Hospitalar }\end{array}$} & $\begin{array}{c}\text { Enfermarias especializadas em } \\
\text { Hospital Geral }\end{array}$ & $\begin{array}{l}06 \text { leitos na Maternidade Evangelina } \\
\text { Rosa }\end{array}$ \\
\hline & $\begin{array}{l}\text { Serviço Hospitalar de Referência para } \\
\text { Atenção às pessoas com sofrimento ou } \\
\text { transtorno mental e com necessidades } \\
\text { decorrentes do uso de crack, álcool e } \\
\text { outras drogas }\end{array}$ & 10 leitos no Hospital do Mocambinho \\
\hline \multirow[t]{2}{*}{$\begin{array}{c}\text { VI - Estratégias de } \\
\text { Desinstitucionalização }\end{array}$} & $\begin{array}{c}\text { Serviços Residenciais Terapêuticos } \\
\text { (SRTs) }\end{array}$ & 5 SRTs \\
\hline & Programa de Volta para Casa (PVC) & 19 Beneficiários do PVC \\
\hline $\begin{array}{l}\text { VII - Reabilitação } \\
\text { Psicossocial }\end{array}$ & $\begin{array}{l}\text { Iniciativas de Geração de Trabalho e } \\
\text { Renda e Empreendimentos Solidários e } \\
\text { Cooperativas Sociais }\end{array}$ & Sem informações \\
\hline
\end{tabular}

Fonte: PEREIRA (2018, p. 124), com base em informações fornecidas pela FMS e SESAPI. 
Neste trabalho, a pesquisadora priorizou o debate de um dos pontos de atenção da RAPS no Estado, sendo ele o correspondente às "Estratégias de Desinstitucionalização". Pontua-se que a desinstitucionalização foi estabelecida como estratégia por meio da portaria n. 2.840, de 29 de dezembro de 2014, do Ministério da Saúde, em que foi criado o Programa de Desinstitucionalização.

No cenário municipal, como se nota pelo quadro acima, os eixos de atenção referentes a esse componente da rede contam com os Serviços Residenciais Terapêuticos (SRTs) e o Programa de Volta para Casa (PVC). Todavia, há que se destacar que no contexto estadual um elemento se particularizou, como mencionado no decorrer desse artigo, elemento este visualizado como estratégia pioneira a nível nacional, caracterizado pelas Equipes de Avaliação e Acompanhamento de Medidas Terapêuticas Aplicáveis à Pessoa com Transtorno Mental em Conflito com a Lei (EAPs), nascente no Piauí no ano de 2015.

Em relação aos SRTs e ao PVC destaca-se que ambos são estratégias distintas de desinstitucionalização, porém associadas como diretrizes políticas de construção do processo de reinserção social de pessoas egressas de instituições psiquiátricas.

No Piauí, os SRTs - compreendidos e regulamentados a partir da portaria 106/2000 como espaços que surgem para acolher e acompanhar PcTMs egressas de longas internações em hospitais psiquiátricos e hospitais de custódia e tratamento psiquiátrico com 2 ou mais anos em vida institucional e que não apresentam condições de garantia de um ambiente adequado de moradia e objetivam viabilizar os cuidados com o segmento de PcTMs que se encontravam desvinculadas da sociedade (FURTADO, 2006) - foram implantados e consolidados efetivando a (des)institucionalização de (18) dezoito PcTMs que viviam internadas em hospitais psiquiátricos do Estado. Três residências de âmbito estadual foram materializadas em três zonas da cidade: centro, zona norte e zona sul e recentemente, no ano de 2015, foi implantada uma residência na zona leste para PcTMs "em conflito com a lei". Em cada residência moram no máximo oito (08) pessoas, alguns moradores são egressos do Hospital Areolino de Abreu, enquanto outros são advindos do extinto Hospital Penitenciário Valter Alencar ${ }^{6}$. É importante ressaltar que no âmbito municipal também se registram estratégias de desinstitucionalização com, atualmente, duas residências: uma na cidade de Teresina na zona sul e a outra na cidade de União.

\footnotetext{
${ }^{6}$ Registra-se que o HPVA, que vinha recolhendo as pessoas com transtorno mental do Sistema Prisional do Piauí desde o ano de 1996, foi extinto da estrutura administrativa da Secretaria de Estado da Justiça do Piauí no ano de 2016 em cumprimento aos direitos e garantias fundamentais previstos na Constituição Federal e nos termos da Lei 10.216/2001 e em consonância com a Política Nacional de Atenção Integral à Saúde das Pessoas Privadas de Liberdade (PNAISP).
} 
No tocante ao PVC - estabelecido pela Lei Federal no 10.708, de 31 de julho de 2003, que institui o pagamento de um benefício mensal no valor de $\mathrm{R} \$ 412,00$ durante o período de 1 ano, podendo ser renovado para pessoas com longo processo de institucionalização em hospitais psiquiátricos, tendo como objetivo contribuir efetivamente para o processo de inserção social, favorecendo o convívio social, de forma a assegurar o exercício pleno de seus direitos (PEREIRA, 2018) - registra-se que se constitui como auxílio aos moradores dos SRTs e no Piauí foi observado que ele vem permitindo a esse segmento a reconstrução de suas identidades e da cidadania.

Gosto de morar aqui, adoro as meninas, adoro todos daqui, tenho meu dinheirinho e sou independente [...] (MORADORA 1 SRT 2).

[...] quando a gente assim quer comprar alguma coisa a gente entra numa conversa e decide e aí cada um contribui, um dá um tanto outro dá outro tanto, é assim. Sempre existe decisão em conjunto pra tudo [...] (CUIDADORA 2 SRT 2).

Assim, observou-se que na perspectiva jurídico-política, as PcTMs já têm a possibilidade de envolverem-se nas relações sociais, participando da vida econômica e administrando o próprio dinheiro, o que permite também intensificar as trocas sociais, afirmando-as em relações mais igualitárias e empoderadas, o que é visível pelas negociações envolvendo dinheiro entre os próprios moradores e estes e as cuidadoras.

Destarte, compreendendo os SRTs e o PVC enquanto estratégias no seio atual, que envolvem a política de saúde mental, observa-se a necessidade ainda, em relação aos SRTs, de estender a cobertura desses dispositivos residenciais, de qualifica-los e financiá-los adequadamente. Além disso, Ribeiro (2006) aponta que os moradores dos SRTs que recebem o PVC demonstram melhoria no nível de interesse em adquirir e poder trocar objetos, o que lhes proporciona maior autonomia. Contudo, a importância dada a esse programa pelos profissionais ainda é baixa. Lima (2008) identifica que os profissionais conhecem pouco o programa e não conseguem enxergar seu potencial para ações de desinstitucionalização.

Mediante o cenário de desafios vivenciados no contexto que envolve o panorama da política de saúde mental no que tange à desinstitucionalização referente aos SRTs e ao PVC, mas também de implementação de diferentes perspectivas que tem promovido novos olhares em torno do modelo de atenção instituído para a PcTM, pontua-se uma realidade particular 
que o Piauí estabeleceu desde o ano de 2015 como estratégia desinstitucionalizante ${ }^{7}$. Tal realidade se apresenta por meio da institucionalização das EAPs.

As EAPs foram estabelecidas por meio da Portaria $n^{\circ}$ 94/2014 com o redirecionamento da atenção por meio de Portaria $n^{\circ} 1 / 2014$ que instituiu a PNAISP (Política Nacional de Atenção Integral à Saúde das Pessoas Privadas de Liberdade). Caracteriza-se por ser um dispositivo de mediação entre a esfera da justiça e os órgãos responsáveis pela atenção psicossocial, no âmbito do SUS e tem o objetivo de garantir o acompanhamento integral e contínuo dos "pacientes" judiciários (PcTMs em conflito com a lei) no contexto familiar e social, por meio da rede de atenção (BRASIL, 2014).

As EAPs se formaram por conta de um contexto histórico que influenciou seu surgimento que se deu principalmente devido ao cenário de transformação que envolvia o tratamento destinado às PcTMs em conflito com a lei. Esse contexto se inicia a partir de um decreto oficializado em 1903, mas que só vigora em 1921 com a criação do primeiro manicômio judiciário no Brasil na cidade do Rio de Janeiro que mais tarde passa a ser chamado e conhecido por Hospitais de Custódia e Tratamento Psiquiátrico com funções, teoricamente terapêuticas e preventivas para cumprimento da medida de segurança que tem como pressuposto a questão da periculosidade e da inimputabilidade, onde a periculosidade é o fundamento da aplicação da medida de segurança para inimputável que é aquele que não tem discernimento ou perdeu a capacidade dos atos ilícitos que praticou (CARRARA, 2010).

O processo de aplicação da medida de segurança tem envolvido alta complexidade devido à naturalização do vínculo entre doença mental e periculosidade, sendo que o julgamento é feito tendo por base a natureza perigosa da PcTM, que historicamente carrega esse estigma de perigo, o que tem gerado justificativa para clausura por tempo indeterminado de várias PcTMs, muitas vezes por pequenos furtos, danos ao patrimônio, desacato a autoridade, o que teoricamente não devia acontecer já que o artigo 97 do código penal aponta claramente que o cumprimento da medida de segurança na modalidade de privação de liberdade só se justificaria em casos em que o crime fosse realmente passível de reclusão, sendo que em todas as outras espécies de delito, a medida de segurança deveria ser ambulatorial (VENTURINI et al, 2016).

\footnotetext{
${ }^{7}$ Registra-se que o estabelecimento e criação das EAPs no Estado não prefigura em seu objetivo central a proposta de desinstitucionalização, além de não estarem inclusas na portaria que institui a RAPS e determina as estratégias de desinstitucionalização de acordo com a política de saúde mental. Todavia, destaca-se que sua implementação foi singularizada nesse contexto devido à realidade local que demandou necessidades peculiares para o cenário piauiense.
} 
Ademais, a partir disso, constata-se que o código não é aplicado e que, independente do tipo de crime, a questão da periculosidade funciona como base principal do sistema penal brasileiro, priorizando o tratamento asilar, o que acaba inclusive indo na contramão da lei 10.216/01, que direciona as práticas de saúde mental em meio aberto, fora os agravos que são provocados nesse contexto de asilamento que desconecta e fragiliza a PcTM.

Na verdade, com a lei 10.216/01 observou-se essa ineficiência da internação em Hospital de Custódia entendendo que a atenção à saúde mental das PcTMs em conflito com a lei deveria ser ajustada, como aponta Venturini et al.,(2016), às diretrizes do SUS e que o tema exigiria uma abordagem intersetorial, na qual o Ministério da Saúde e o da Justiça deveriam atuar em conjunto e, nessa perspectiva, algumas políticas vão sendo implementadas para a reorientação do modelo de atenção à PcTM em conflito com a lei, através do Plano Nacional de Saúde no Sistema Penitenciário e pela Política Nacional de Atenção Integral à Saúde das Pessoas Privadas de Liberdade e a partir daí são criadas as EAPs.

No Piauí, o histórico das EAPs e de reorientação da atenção às PcTMs em conflito com a lei se dá inicialmente com a interdição do HPVA, localizado no município de Altos, próximo à capital Teresina. O HPVA foi equivalente, embora não legalmente, pois sem vínculo com o SUS, ao Hospital de Custódia e Tratamento Psiquiátrico (HCTP) do Estado do Piauí (PIAUÍ, 2017).

No cenário piauiense, o HPVA se caracterizou como um serviço híbrido, um misto de saúde e segurança, que teve início como um anexo à Penitenciária Major César, em meados de 2004, ou seja, na contramão da reforma psiquiátrica. Quando o hospital foi vinculado à Secretaria de Justiça do Estado, foi solicitada a realização de inspeção e graves irregularidades foram constatadas (quanto à estrutura física e à própria violação de direitos humanos). Mediante essa inspeção foram gerados relatórios que deram base para o Ministério Público fazer requerimento, especificamente no ano de 2012, para interdição desse local (NASCIMENTO et. al, 2017).

Desde então, foram sendo feitos tensionamentos pela justiça do Estado do Piauí para que fosse realizada a transinstitucionalização, ou seja, retirada das PcTMs para outras instituições similares, sendo que a tramitação ocorreu para o HAA considerando a grave situação no HPVA.

O processo desse redirecionamento se deu com o encaminhamento inicial de 23 pacientes internados no HPVA para o HAA no ano de 2014, o que gerou colapso devido ao quantitativo de leitos destinados à internação integral, além da resistência, estigma, medo e 
preconceito por parte dos profissionais e conselhos de classe como o Conselho Regional de Medicina (CRM) que não aceitaram tais direcionamentos (NASCIMENTO et. al, 2017).

Mediante o cenário caótico, no final do ano de 2014 a Secretaria de Estado da Saúde (SESAPI), fomentada pela situação instalada, estabeleceu parceria técnica com a Secretaria de Estado da Justiça (SEJUS), Tribunal de Justiça, Ministério Público, traçando ações e metas com a finalidade de redirecionar o modelo de atenção à saúde mental destas PcTMs em conflito com a lei.

No seio dessa realidade é que foram se figurando e se constituindo as EAPs. Em relação a esse histórico formativo das EAPs, sua função e caracterização registra-se a fala das entrevistadas que acompanharam o processo de inserção das equipes no Estado do Piauí:

[...] eu acompanhei o processo de composição, eu não fazia parte da equipe, né? Fazia parte só da gerência, trabalhava aqui pela manhã. E aí a gente acompanhou todo o processo de construção. A EAP é um pedaço de uma colcha maior, né? Então a gente acompanhou o processo de formação e quando essas equipes começaram a trabalhar eu já entrei já no quase que no finalzinho do primeiro ano de atividade da EAP [...]. Foi um serviço que assim, foi implantado e começou a funcionar, né? Ele foi incentivado pelo Ministério da Saúde em 2014, né? Que foi quando o Estado resolveu aderir à política e também a questão de implantação do serviço, né? Que são duas equipes, mas é conhecida como serviço de avaliação e monitoramento da pessoa com transtorno mental em conflito com a lei. E aí o Estado foi habilitado com duas equipes, mas essas duas equipes só vieram a funcionar de fato e de direito em maio de 2015 (PROFISSIONAL 4).

Na realidade a EAP é um braço da política, né, da PNAISP só que assim, o próprio Ministério desenhou a EAP, mas não sabe, ele não tinha como imaginar que como isso ia ser operacionalizado e como isso e iria ter uma continuidade, até porque era o início de uma política, né? A política é de 2014 é uma coisa muito recente né? E a EAP ela trabalhou com as especificidades do Piauí, né? Que a gente sabe que no Maranhão, por exemplo, a especificidade é outra, né? Aqui é uma equipe a nível de secretaria de Estado, então ela é referência para 224 municípios, faz atendimento dos pacientes de qualquer município, né? E por isso que ela é uma equipe difusa e nessa perspectiva de que ela também não faz assistência, não faz a perícia, mas ela conecta todas as políticas públicas que aquela pessoa com transtorno mental em conflito com a lei necessita independente do tipo de medida de segurança que essa pessoa vá ter, né? Então é uma EAP que é muito difusa, é muito volante [...] (PROFISSIONAL 4).

[...] essa equipe, ela é da saúde, ela não é do Ministério da Justiça, mas a gente trabalha em parceria porque os detentos estão lá, né? E a minha visão é que é extremamente necessária porque o louco infrator, o crime é concebido muitas vezes do surto psicótico dessas pessoas que não recebem tratamento. E elas chegam como criminosos nas cadeias e lá elas não podem ficar. Foi importante e ainda hoje é (PROFISSIONAL 2).

EAPs são equipes ligadas à Frente Nacional da Pessoa Privada de Liberdade que é um traço nessa política, um ramo específico. E as EAPs são equipes de saúde mental ligadas à política da pessoa privada de liberdade (PROFISSIONAL 5). 
Tendo por base os relatos acima, percebe-se que o trabalho das EAPs no Estado visava romper com a lógica dominante de apartação social e abandono, deslocando a atenção do regime hospitalar para o comunitário, buscando promover, dessa forma, a atenção integral das pessoas com transtornos mentais submetidas à medida de segurança pela lógica do sistema público de saúde, afastando-as, portanto, de um olhar isolado da justiça e possibilitando a construção de um novo olhar, o da cidadania (PIAUÍ, 2017), com intensa intersetorialidade, mas, abarcando todos os municípios e constituindo-se como uma equipe com um formato bem flexível, volante, o que permitia trânsito e dinamicidade, mas, abarcando várias frentes simultâneas, inclusive conectar várias políticas para atender diversas necessidades no horizonte da integralidade.

Efetivamente, as EAPs iniciaram seu trabalho no ano de 2015 com a realização de avaliações biopsicossociais (censo psicossocial) das PcTMs que foram internadas no antigo HPVA e no HAA, sendo um processo complexo, pois não se tinham dados fidedignos sobre a demanda existente no sistema penitenciário do Estado, no que diz respeito à quantidade de pacientes com transtornos mentais provisórios judicialmente em medida de segurança, com guia de internação, procedência, etc. Após esse levantamento foi gerado relatório com Projetos Terapêuticos Singulares (PTS), discutidos e encaminhados ao Secretário Estadual de Saúde, Secretário de Justiça e Juiz do Tribunal de Justiça através da Vara de Execução Penal, sendo induzida a criação de mais 03 SRTs no Estado, instituídos pela portaria no 3090 de 23 de dezembro de 2011 no âmbito do SUS, em que de imediato um SRT foi criado e há a previsão da implantação de mais um quantitativo de dois (NASCIMENTO et. al, 2017).

Alguns desafios se consolidaram para a engrenagem do trabalho das EAPs no Estado, dentre eles destaca-se a implantação de SRTs, pois embora fossem considerados como elementos e estratégias necessárias à desinstitucionalização das PcTMs em conflito com a lei, barreiras como a contratação de pessoal e temores dos profissionais foram encontradas

[...] teve " $n$ " questões administrativas na Sesapi, principalmente com recursos humanos que o Estado entrou naquele período que não podia contratar mais ninguém $[\ldots] . .$. a gente chegou até a alugar o imóvel e tudo, mas não teve como contratar o pessoal porque eles entraram naquele negócio administrativo de improbidade administrativa [...] limite prudencial que eles chamam de contratação (PROFISSIONAL 5).

[...] num primeiro momento teve muita resistência, ninguém quer fazer esse acolhimento, mas deu certo. Depois as coisas foram, os medos sendo minimizados, eu acho que era mais medo mesmo da equipe (PROFISSIONAL 4). 
Além do fato do SRT ser um serviço que é para ser implantado em nível de gestão municipal e que o Estado acabou assumindo, haja vista a gestão municipal ter resistido historicamente a processos desinstitucionalizantes, o que ocorreu por força dos Termos de Ajustamentos de Conduta imposto pelo Ministério Público. Na pesquisa realizada foi detectado que cerca de $27 \%$ de PcTMs em conflito com a lei tem avaliação de perfil para inserção em SRT, mas o percentual demonstrado de efetiva inserção é de $5 \%$, o que demonstra a necessidade de investimento do poder público em novos dispositivos.

Ademais, o próprio estigma e o preconceito também foram observados, porque se desinstitucionalizar a PcTM em geral já é complicado, fazer isso com o PcTM em conflito com a lei configura um processo ainda mais complexo.

\begin{abstract}
E aí é um tema difícil pra se dialogar que é o paciente em conflito com a lei, mas de início a gente vem trabalhando, essa equipe EAP ela é fantástica quanto a isso porque, se o paciente com transtorno mental é difícil de desinstitucionalizar, o paciente em conflito com a lei é o cubo [...] a partir de então, não tinha mais esse negócio de dizer que a residência não ia receber em conflito com a lei, toda e qualquer residência vai receber todo e qualquer paciente. $\mathrm{E}$ isso foi um tumulto também... E ainda teve caso, por exemplo, agora no final de 2018 um morador que é de uma pessoa importante da gestão de Teresina que foi reclamar ao Secretário de Saúde que não queria aquela casa ali daqueles drogados ali não, daquelas pessoas que eram da Major Cesar, perto da casa da mãe dele. É assim bárbaro uma situação dessas (PROFISSIONAL 5).
\end{abstract}

Percebeu-se que o estigma que ronda o segmento é uma constante, inclusive da vizinhança, que ao tomar conhecimento do processo em curso, tende a resistir.

Dessa forma, o processo de desinstitucionalização, na verdade, desde a sua parte inicial, foi cercado por muitas incertezas, com uma equipe composta pelo ente federal, sem respaldo legal local, em que o coletivo que a integrava tomou para si a responsabilidade de fazer acontecer o processo. Claro que tinha respaldo na Secretaria de Saúde, da Justiça e no Juiz, e também o contexto era favorável. Mas, o que se destaca é que, embora representasse uma política pública consolidada, ainda era circundada de incertezas, e muitos aspectos acabavam ficando sob responsabilidade dos profissionais, ou seja, o peso do processo pairava sobre eles, embora tivessem o apoio da gestão maior do processo.

Ademais, foram perceptíveis outros desafios presentes no processo de trabalho das EAPs, como a questão da rede que ainda se encontra fragmentada e precarizada, ocasionando um processo complexo para a divisão e articulação do cuidado, bem como do que foi notado pelos dados da pesquisa, em que foi verificado que 16,67\% das PcTMs retornaram para casa e ainda uma média de $33,50 \%$ se encontram em transição para o convívio familiar por motivos inúmeros, seja pelas condicionalidades da família que, muitas vezes, tem dificuldade de 
retomar a vivência com essa PcTM, seja pelos entraves na dinâmica com o judiciário que muitas vezes apresenta morosidade em sentenciar e avaliar a situação da PcTM em conflito com a lei, provocando muitas vezes até o óbito desse paciente.

Quanto à questão da rede como desafio das EAPs, destaca-se que a RAPS ficou isolada e ao mesmo tempo parece ter se isolado, permitindo concluir como os gestores e profissionais se apropriaram do ideário da reforma e como o colocaram em ação, por isso a importância de investir em qualificação e preparo profissional e também de buscar efetivá-los no serviço, para que seja possível dar continuidade e avançar na proposta de desinstitucionalização.

Quantos aos avanços desse trabalho das EAPs, foi possível observar como produto o baixo índice de (re)internação, mostrando que pode ser possível a reinserção de um público que cometeu um ilícito, mas nem por isso deve reincidir. Além disso, o Piauí, por meio dessas equipes, foi se consolidando como parâmetro e estratégia no que tange ao processo de trabalho com as PcTMs em conflito com a lei, despontando no rol das boas práticas em saúde mental como inovador,/modelo também de processos desinstitucionalizantes devido à realidade posta pelo próprio Estado.

[...] logo depois que o paciente está inserido na família ainda continua o monitoramento, porque a equipe tem essa finalidade de fazer o monitoramento e avaliação constante. A gente só teve, se não me engano foi um ou dois casos de reinternação (PROFISSIONAL 5).

O processo é feito com muita sutileza, conquistando paulatinamente a adesão familiar, tecendo a rede socioassistencial do território de cada família, com ênfase no Centro de Referência e Assistência Social (CRAS) e CAPS, e garantia de retaguarda da equipe da Eap, no monitoramento do processo.

Desta feita, é possível afirmar que o trabalho das EAPs no Piauí foi importante, haja vista que propiciou um novo olhar às PcTMs em conflito com a lei, buscando avançar e superar os desafios impostos, muito embora seja válido mencionar que ainda há muito o que ser percorrido em prol da efetividade da rede de saúde mental que considere as premissas da política de saúde mental no contexto da desinstitucionalização, principalmente considerando as várias mudanças no cenário de saúde mental, tendo por principal marco o estabelecimento da portaria $\mathrm{n}^{\circ} 3.588 / 2017$, que prevê o retorno do papel dos hospitais psiquiátricos, passando a serem financiados pelo poder público e, agora, fazendo parte da RAPS (BRASIL, 2017). 
Tal questão acarreta em barreiras para a plena consolidação e avanços das estratégias desinstitucionalizantes, inclusive no Piauí, que, no caso das EAPs, tem se deparado recentemente com um panorama de inconsistências, haja vista ter sido extinto enquanto serviço por meio da Portaria GM/MS n. 1325, de 18 de maio de 2020 e ter sido revogado em julho do mesmo ano pelo Ministério da Saúde em virtude dos questionamentos advindos de diversas instituições, organizações e especialistas, incluindo o Conselho Nacional de Justiça (CNJ) que solicitou esclarecimentos à Secretaria Executiva do Ministério da Saúde sobre a extinção do serviço e sobre a existência de ações e estratégias capazes de substituí-lo, especialmente nas unidades da federação que já haviam habilitado as EAPs, como no caso piauiense (CONJUR, 2020).

Segundo a mesma fonte acima, o CNJ pontuou que o serviço das EAPs desempenha importante papel, afirmando, ainda, que a complexidade que envolve o tratamento adequado a esse segmento populacional ultrapassa o âmbito da justiça e impõe uma atuação intersetorial, que ficaria prejudicada com a extinção dessa política pública. De acordo com o CNJ, as PcTMs em conflito com a lei mantidas em HCTPs ou outros espaços com essa finalidade passariam a sobreviver em situação de vulnerabilidade ainda maior com o fim do serviço.

Assim, na esteira do processo desinstitucionalizante prefigura-se que o cenário piauiense consolidou avanços, verificados por meio das estratégias de desinstitucionalização adotadas, porém, pondera-se que os desafios precisam ser superados, haja vista que quando se trata da EAP, inclusive, o que se percebe é que o trabalho, apesar de ser realizado pelas equipes (muito embora com algumas inconsistências e incertezas) considerando a concepção da desinstitucionalização como (des)construção, ainda se estabelece com resistências: seja pela rede intersetorial que se apresenta de forma precarizada e fragmentada, o que torna a divisão de cuidados comprometida, sobrecarregando a EAP que teve realmente que negociar e pactuar o acontecimento do processo; seja pela própria comunidade, pois essa política visa ao cuidado comunitário e se observa que as PcTMs ainda sofrem com o estigma e o preconceito social.

\section{CONSIDERAÇÕES FINAIS}

Para expor a formação do desenho de desinstitucionalização no Estado do Piauí e como este foi configurado, a pesquisadora apontou suas nuances e particularidades, elencando tal contexto no que concerne aos aspectos contributivos para o processo (des)institucionalizante, principalmente a partir das EAPs. 
Desta feita, foi possível verificar que a desinstitucionalização enquanto produto advindo do Movimento de Reforma Psiquiátrica, pode ser entendida, de acordo com Amarante (1997), não como um método ou dogma, mas como uma estratégia que não se alcança de forma completa e perfeita, pois se trata de um processo permanente no que diz respeito aos entendimentos culturais, sociais e técnicos no lidar com o sofrimento, com as situações de diferenças e diversidades, ou seja, é a ideia mesmo de desconstrução e de um processo contínuo que reinventa novas formas sociais no lidar com a loucura, a diferença e o sofrimento humano.

No Piauí, o processo de (des)institucionalização ainda se em construção, haja vista o próprio início ter sido tardio e configurado a partir de estratégias previstas como eixos da RAPS, a saber: os SRTs, o PVC e, num panorama singular, as EAPs que foram instituídas e habilitadas recentemente, em 2015, por meio da Portaria nº 94/2014.

Apesar de não serem localizadas como estratégia prevista legalmente, as EAPs no Estado, pelas circunstâncias apresentadas em virtude da interdição do HPVA e do próprio redirecionamento de atenção que passava a ser construído em torno da PcTM em conflito com a lei, configuraram-se como relevante mecanismo à medida que, considerando os ideais e preceitos de reforma psiquiátrica, buscaram consolidar, desde o momento de sua implantação, um processo de (des)institucionalização característico e à luz da perspectiva de (des)construção. Contudo, há que se mencionar que ainda existe um longo caminho para efetivação desse processo, pois na relação imposta pelo panorama de desinstitucionalização é necessário, sobretudo, refletir sobre o cuidado em saúde mental e a relação estabelecida entre as interfaces que permeiam esse cenário.

\section{REFERÊNCIAS}

AMARANTE, P. D. C. (Org.) Loucos pela vida: a trajetória da reforma psiquiátrica no Brasil. Rio de Janeiro: SDE/ENSP, 1995.

AMARANTE, P. D. C. O homem e a serpente: outras histórias para a loucura e a psiquiatria. Rio de Janeiro: Fiocruz, 1996.

AMARANTE, P. D. C. Loucura, cultura e subjetividade: conceitos e estratégias, percursos e atores da reforma psiquiátrica brasileira. In: Fleury, S. (org.). Saúde e Democracia: a luta do CEBES. São Paulo: Lemos Editorial, 1997. p. 163-185.

AMARANTE, P. D. C. Saúde Mental e atenção psicossocial. Rio de Janeiro: Fiocruz, 2007. 
AMARANTE, P. D. C. Saúde Mental, Desinstitucionalização e Novas Estratégias de Cuidado. In: GIOVANELlA, L. et. al (Org.). Políticas e Sistema de Saúde no Brasil. 2 ed. Rio de Janeiro: Editora FFIOCRUZ, 2012, p. 635-655.

ARCOVERDE, A. C. B. Metodologias qualitativas de pesquisa em Serviço Social. Recife: Ed. Universitária da UFPE, 2013.

BRASIL. Ministério da Saúde. Portaria no 3.588, de 21 de dezembro de 2017. Brasília, $2017 . \quad$ Disponível em: http://bvsms.saude.gov.br/bvs/saudelegis/gm/2017/prt3588_22_12_2017.html

BRASIL. Ministério da Saúde. Portaria n.94, de 14 de janeiro de 2014. Brasília, 2014. Disponível em: http:// bvsms.saude.gov.br/bvs/ saudelegis/gm/2014/ prt0094_14_01_2014.html.

BRASIL. Ministério da Saúde. SAS/ DAB. Legislação sobre Rede de Atenção Psicossocial - Portaria no 3.088/ 2011, Brasília, DF, 2011.

BRASIL. Ministério da Saúde. Saúde Mental no SUS: acesso ao tratamento e mudança do modelo de atenção. Relatório de Gestão 2003-2006. Ministério da Saúde: Brasília, 2007.

BRASIL. Ministério da Saúde "Reforma Psiquiátrica e política de saúde mental no Brasil". In: Conferência Regional da Reforma dos Serviços de Saúde Mental: 15 anos depois de Caracas. Brasília, novembro de 2005.

BRASIL. Ministério da Saúde. Lei no 10.708/2003. Manual do programa “De Volta Para Casa”. Brasília, 2003.

BRASIL. Ministério da Saúde. Secretaria de Atenção à Saúde. Portaria 336/GM de 19 de fevereiro de 2002. Brasília, 2002.

BRASIL. Ministério da Saúde. Portaria n. 224 de 29 de janeiro de 1992. Estabelece diretrizes e normas para o atendimento em saúde mental. Diário Oficial da República Federativa do Brasil. Brasília, DF, 29 jan. 1992. Seção 1.

CARRARA, S. L. A história esquecida: os manicômios judiciários no Brasil. Revista Brasileira de Crescimento e Desenvolvimento Humano, v.20, n.1, p.16-29. 2010.

CONJUR. Revista Consultor Jurídico. Disponível em: https://www.conjur.com.br/2020-jul16/extincao-apoio-presos-transtornos-mentais-revertida. Acesso em 21/09/2020 às 10:47.

DELGADO, P. G. et al. Reforma psiquiátrica e política de saúde mental no Brasil. In: MELLO, M. F.; MELlO, A. A. F.; KOHN, R. (Org.). Epidemiologia da saúde mental no Brasil. Porto Alegre: Artmed, 2007. p. 39-83.

FURTADO, J. P. Avaliação da situação atual dos Serviços Residenciais Terapêuticos no SUS. Ciência e Saúde Coletiva, 2006, 785-95.

GIL, A. C. Métodos e Técnicas de Pesquisa Social. 6ª ed. Editora: Atlas, 2008. 
GIL, A. C. Como elaborar projetos de pesquisa. São Paulo: 2 ed, Editora Atlas. 2002.

LIMA, S.C. $O$ Programa de Volta para Casa em Fortaleza: o que mudou na vida de seus beneficiários. 2008. 129p. Dissertação (Mestrado em Políticas Públicas e Sociedade) - Centro de Humanidades, Universidade Estadual do Ceará, Fortaleza, 2008.

MINAYO, M. C. S. (Org.). O desafio do conhecimento: pesquisa qualitativa em saúde. 11. ed. São Paulo: Hucitec, 2008.

MINAYO, M. C. S. O desafio da pesquisa. In: MINAYO, M. C. S (Org.). Pesquisa social: teoria, método e criatividade. 21ed. Petrópolis, RJ: Vozes, 2002. p. 18- 29.

NASCIMENTO, G. M. N. et. al. Considerações sobre o redirecionamento do modelo de atenção à saúde mental das pessoas com transtorno mental em conflito com a lei no Estado do Piauí no ano de 2014 a 2016. In: PEREIRA, S. L. B et. al. A política de saúde mental no Piauí sob a égide da RAPS. Teresina : EDUFPI, 2017.

PEREIRA, S. L. B. Intersetorialidade na política de saúde mental: uma análise a partir das articulaçoes tecidas pelos/as assistentes sociais nas redes intersetoriais. Tese (Doutorado em Políticas Públicas) - UFPI, Teresina, 2018, 292 p.

PIAUÍ. Secretaria de Estado da Saúde. Gerência de Atenção à Saúde Mental. Uma porta, várias saídas: Resgatando a cidadania. Cartilha, Gerência de Atenção à Saúde Mental, Teresina-PI, 2017.

PINTO, A. T. M.; FERREIRA, A. A. L. Problematizando a reforma psiquiátrica brasileira: a genealogia da reabilitação psicossocial. Psicologia em Estudo, Maringá, v. 15, n. 1, p. 27-34, 2010 .

RIBEIRO, I. P. De Volta para Casa: estudo com egressos de hospitais psiquiátricos. 2006. 97p. Dissertação (Mestrado em Psicologia da Saúde) - Universidade Metodista de São Paulo, São Bernardo do Campo, 2006.

ROSA, L. C. S. Classes sociais, gênero e etnias na saúde mental. Teresina: EDUFPI, 2013, 412p.

ROSA, L. C. S. A Política e as ações em saúde mental do Piauí: as dimensões transformadoras da década 2000 a 2010. In: ROSA, L. C. S; BONA, M. E. C; MACEDO, J. P. Política e ações de saúde mental no Piauí: 2000 a 2010. Teresina: EDUFPI, 2011, 244 p.

ROTELli, E et al. Desinstitucionalização: uma outra via. In: N1CÁClO, E (Org.). Desinstitucionalização. 2. ed. Sao Paulo: HUCITEc, 1990.

SCAlZAVARA, F. A operacionalização da Reforma Psiquiátrica Brasileira- um estudo sobre a percepção dos profissionais do CAPS Ponta do Coral de Florianópolis. Dissertação (Mestrado em Serviço Social). Universidade Federal de Santa Catarina, 2006, 136 p.

SOARES, J. M. A. S. Engenho dentro de casa: sobre a construção de um serviço de atenção diária em saúde mental. Dissertação apresentada à Escola Nacional de Saúde Pública para obtenção do grau de Mestre. Fundação Oswaldo Cruz, Rio de Janeiro, 1997, 111 p. 
SPRICIGO, J. S. Desinstitucionalização ou desospitalização: a aplicação do discurso na prática psiquiátrica de um serviço de Florianópolis. Florianópolis: UFSC/PEN, 2002. 147 p. (Teses em Enfermagem, 42).

VENTURINI, E. et. al. Louco Infrator e o Estigma da Periculosidade. Brasília: CFP, 2016. 356 .

VIDAL, C. E. L. et. al. Reforma psiquiátrica e serviços residenciais terapêuticos. Jornal Brasileiro de Psiquiatria, Rio de Janeiro, v. 57, n. 1, p. 70-79, 2008 .

VIEIRA, G. T. S. A família e o provimento de cuidados à pessoa com transtorno mental no contexto da desinstitucionalização. Dissertação de Mestrado em Serviço Social. UFPE. Recife, 2009, 108 p.

WAIDMAN, M. A. P. O trabalho de cuidados às famílias de portadores de transtornos mentais no paradigma da desinstitucionalização. Tese (Doutorado em Enfermagem) Universidade Federal de Santa Catarina, Santa Catarina, 2004, 277 p.

\section{Como Referenciar este Artigo, conforme ABNT:}

ROSA, L. C. S; SILVA. S. L. C. O Cenário de (Des)Institucionalização em Saúde Mental do Piauí a Partir das EAPS. Rev. FSA, Teresina, v.18, n. 01, art. 15, p. 327-353, jan. 2021.

\begin{tabular}{|l|c|c|}
\hline \multicolumn{1}{|c|}{ Contribuição dos Autores } & $\begin{array}{c}\text { L. C. S. } \\
\text { Rosa }\end{array}$ & $\begin{array}{c}\text { S. L. C. } \\
\text { Silva }\end{array}$ \\
\hline 1) concepção e planejamento. & $\mathrm{X}$ & $\mathrm{X}$ \\
\hline 2) análise e interpretação dos dados. & $\mathrm{X}$ & $\mathrm{X}$ \\
\hline 3) elaboração do rascunho ou na revisão crítica do conteúdo. & $\mathrm{X}$ & \\
\hline 4) participação na aprovação da versão final do manuscrito. & & $\mathrm{X}$ \\
\hline
\end{tabular}

